Acta Geod. Geoph. Hung., Vol. 38(3), pp. 327-335 (2003)

\title{
LOCAL EFFECTS DISTURBING THE MONITORING OF TECTONIC MOVEMENTS OF THE MECSEKALJA FAULT BY SHALLOW DEEP BOREHOLE TILTMETERS IN HUNGARY
}

\author{
G Mentes ${ }^{1}$
}

[Manuscript received June 8, 2001]

\begin{abstract}
In autumn of 1997 two borehole tiltmeters, type Applied Geomechanics, A722 were installed for monitoring recent movements of the Mecsekalja fault in Southwest Hungary. Beside the continuous tilt measurements a geodetic network for GPS and electronic distance measurements (EDM) and a levelling line crossing the fault were established. The borehole tiltmeters are continuously recording and the geodetic measurements (GPS, EDM, precision levelling) are repeated twice in a year, in spring and in autumn.

This paper presents experiences and results of the tiltmeter measurements and analyses the disturbing effects e.g. earth tide, tilt caused by ground water level variations, precipitation of the surrounding vegetation, etc. superposed to the tilt signal. The paper shows some of these effects which can use to prove the goodness of the coupling between the instrument and the ground.
\end{abstract}

Keywords: borehole; deformation; landslide; local effect; tectonic movements; tiltmeter

\section{Introduction}

Geodynamical deformation measurements play a very important role in the investigation of recent crustal movements and local deformations at the locations of large industrial objects, e.g. dams, nuclear power stations, deposits of dangerous materials, etc. The geodetic measurements (GPS, EDM, precise levelling) give results with poor time resolution. To study the physics of crustal and local deformations e.g. landslides and to give an alarm signal if the rate of the deformation suddenly increases continuously recording methods are needed. For these purposes high sensitive borehole tiltmeters can be used because their installation is relatively of low cost and boreholes ensure a very stable place for the instruments.

The high sensitive tiltmeter measurements are disturbed by local effects which can be in the same or higher order of magnitude than the tectonic movements of the fault. The disturbing effects of tilt measurements can be local geodynamical processes, e.g. landslides and the influence of the variations of environmental parameters. These later can cause both direct effects, as the variation of temperature, barometric pressure, ground water, etc. and indirect effects as e.g. hang slides caused by ground water level variations. These local influences must be separated from the

\footnotetext{
${ }^{1}$ Geodetic and Geophysical Research Institute of the Hung. Acad. Sci., H-9401 Sopron, POB 5 , Hungary
} 
tiltmeter data to obtain the movements of the fault. Some disturbing effects as earthquakes, earth tide, tilts caused by the variation of the ground water level and precipitation of the surrounding vegetation give us information about the coupling of the instrument and the ground.

Since 1994 a lot of test measurements have been carried out on several sites in the Lower Rhine Embayment, Western Germany, and near the town Sopron in Hungary to find connection between ground tilts and local disturbing effects e.g. temperature, air pressure, groundwater levels, precipitation, etc. (Kümpel et al. 1996, Lehmann et al. 1998, Rebscher 1996).

In 1997 a complex measuring network was established to investigate the movements of the Mecsekalja-fault in Hungary. The displacements are determined by GPS, electronic distance measurements (EDM) and precise levelling twice in a year and continuously by two biaxial bubble borehole tiltmeters installed at both sides of the fault. According to the results of the measurements both the geodetic and the tilt measurements show annual variations. The combination of the continuous, high sensitive tiltmeter and the repeated geodetic measurements contributes to filtering of local disturbing effects from tiltmeter data and to study the annual variations of the data obtained by geodetic measuring methods on the one hand and to understand physics of global and local geodynamic processes, e.g. tectonic movements, landslides, etc. on the other hand.

\section{Description of the tiltmeters}

The tilt measurements have been carried out by the dual-axis borehole tiltmeters Model 722 made by Applied Geomechanics Inc. (AGI), Santa Cruz, California. This tiltmeter consists of a cylindrical stainless steel body $(85 \mathrm{~cm} \mathrm{long,} 5.4 \mathrm{~cm}$ in diameter) containing two orthogonal electrolytic precision tilt sensors, amplifiers and signal filters for each of them and a temperature sensor. The tiltmeter is connected to the data logger via a submersible steel-reinforced cable and an external switch box. The resolution of the instrument in a measuring range of $\pm 200 \mu \mathrm{rad}$ is $0.1 \mu \mathrm{rad}$ and in a range of $\pm 2000 \mu \mathrm{rad} 1 \mu \mathrm{rad}$. The instruments are calibrated by the method developed at the Geodetic and Geophysical Research Institute in Sopron (Hungary) and at the Geological Institute, Section Applied Geophysics, Bonn University (Mentes 1986, Mentes 1998, Mentes et al. 1996).

The tiltmeters are usually installed in shallow boreholes at depths between 2 and $8 \mathrm{~m}$. The borehole has to be drilled with a diameter of about $30 \mathrm{~cm}$, its casing is a PVC pipe that is coupled to the surrounding formation by concrete. Inside the pipe the instrument is fixed by quartz sand in order to obtain a strong coupling to the ground. The signal is transferred via cable to the switch box which is placed in a trunk at the surface together with the power supply and a data logger (Fig. 1).

Acta Geod. Geoph. Hung. 38, 2003 


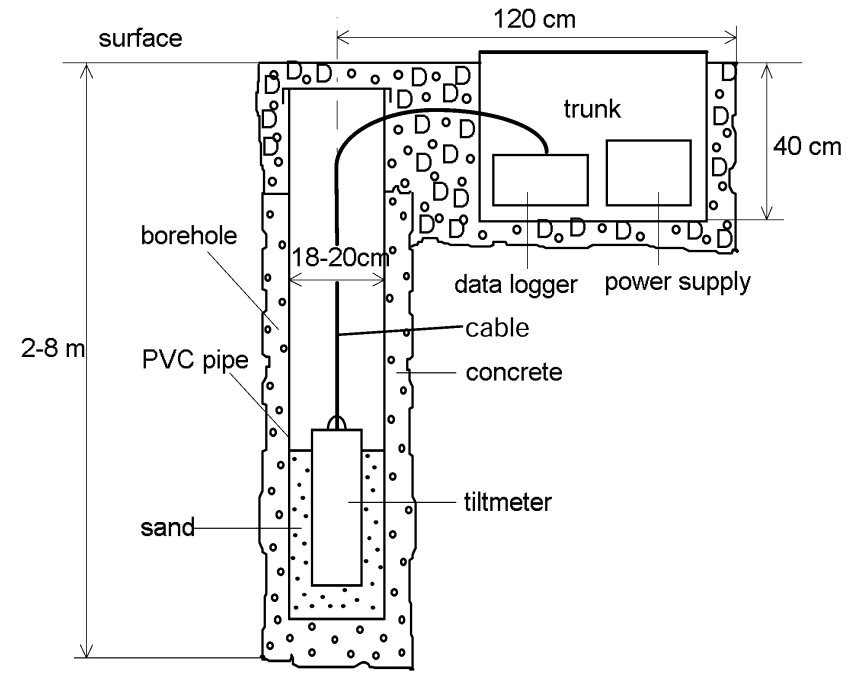

Fig. 1. Installation of the Model 722 tiltmeter in the borehole

\section{The site of the measurements}

Figure 2 shows the site of the measurements at the Mecsekalja-fault (pecked line in the map) in the southwestern part of Hungary. The pillars for the GPS and EDM measurements (number of points: 4371, 4366, 4466, 2052) are marked by squares and the circles designate the levelling line. The end points of the levelling line (point numbers: 1001, 1004) are placed directly on the bedrock. Two other points of the levelling line (point numbers: 100, 200) and the GPS points are deep founded concrete pillars. The tiltmeters are placed at the ends of the levelling line. At the point D1 the whole borehole is drilled in the bedrock and it has a depth of $3.6 \mathrm{~m}$. At the point $\mathrm{D} 2$ the borehole has a depth of $8 \mathrm{~m}$. The deepest part of the borehole is in the bedrock ( $0.8 \mathrm{~m}$ from the bottom) and its upper part (7.2 $\mathrm{m}$ from the surface) is in loess. The borehole is here at the bottom of a hill. The place of the instrument is surrounded by the hill from North and partly from West and by a meadow from the other sides, therefore this tiltmeter is strongly disturbed by hang slides. The hill is covered by a forest, so the transpiration of the trees causes local disturbances in the tilt measurements (Rebscher 1996).

North of the fault the bedrock is Jurassic limestone and south of it granite. The Y-direction of both tiltmeters is N-S, so the tiltmeters record tilts of the same directions. The sampling period of the tiltmeters is 1 hour. The tiltmeters were installed at the beginning of October, 1997 and the measurements have been carried out continuously since 13.10.1997. 


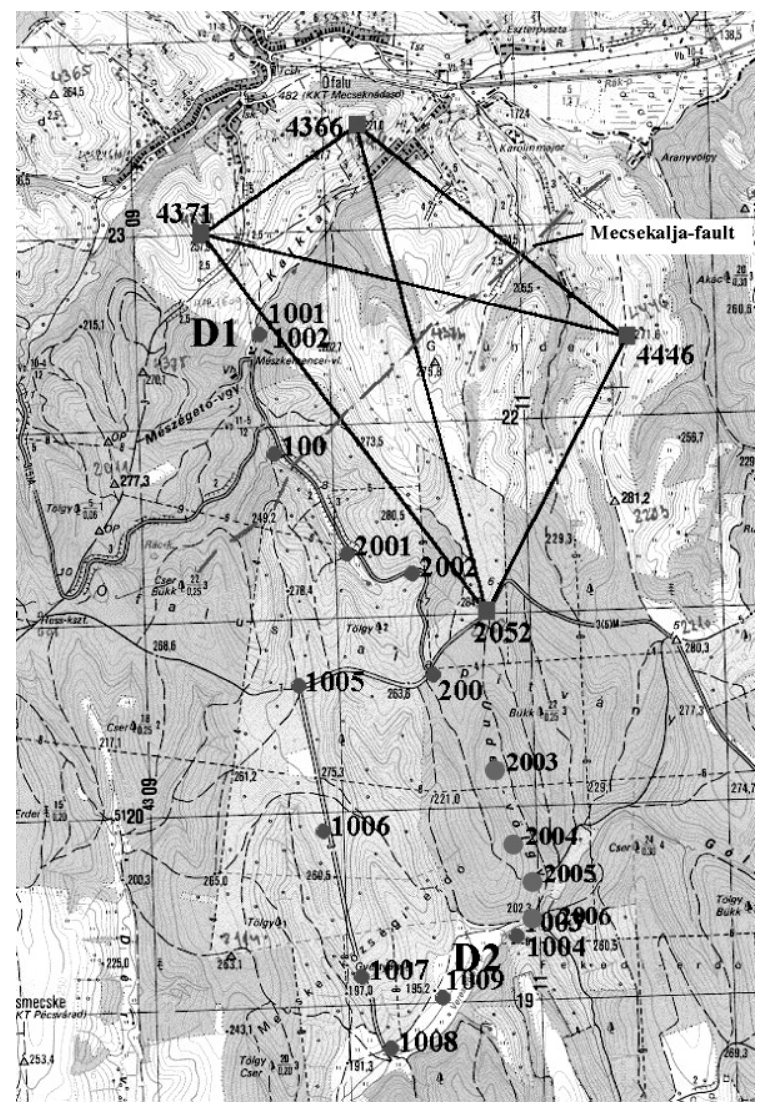

Fig. 2. The map of the site of the measurements

\section{Results of the tilt measurements}

Figures 3 and 4 show the raw data recorded at the points D1 and D2 respectively from 01.01.1998 till end of 2000. The figures show that the tilts at the north end of the levelling line, at the point D1 are in both directions in the range of about some microradians, much less than at the point D2 where the tilt changes within the range of about some 10 microradians. Especially, the tilt variation was very large at the beginning of the recording. The reason of this was that the borehole was not made water-proof and therefore the stabilization of the instrument needed much more time than the tiltmeter at the point D1. Since the end of the year 1998 the tiltmeter at the point D2 has been working more stable than before and since then it has recorded a slow tilt in south-west direction. The tilt variation is in the direction X (East) within 10 microradian and in the direction $\mathrm{Y}$ (North) in a range of about 40 microradian.

The borehole at the point D1 was overrun by water during a heavy rainfall in the spring of the year 1999 and after it this tiltmeter became much more unstable. 


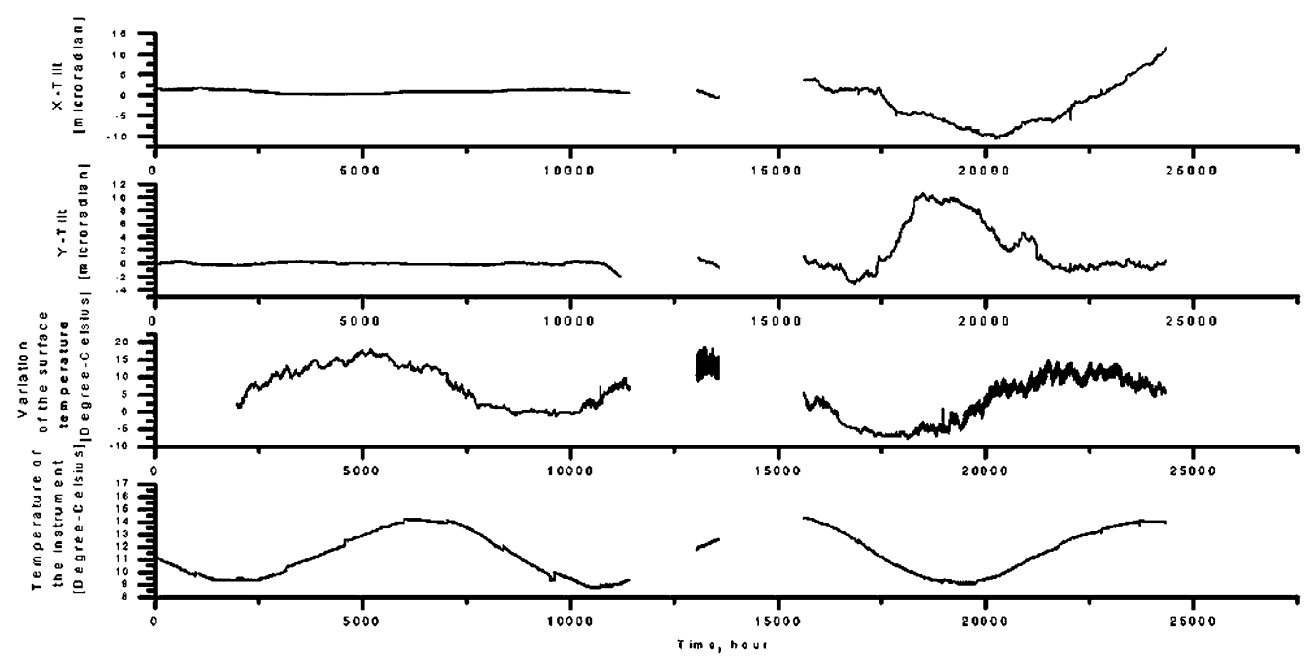

Fig. 3. Row data recorded at the point D1 from 01.01.1998 till 31.12.2000

In spite of this the tilt variation is less than 10 microradian and the direction $\mathrm{Y}$ is so stable again as before the overrun by water.

The temperature in the borehole $\mathrm{D} 1$ (temperature of the instrument) varies between $9^{\circ} \mathrm{C}$ and $14^{\circ} \mathrm{C}$ because the depth of this borehole $(3.6 \mathrm{~m})$ is not sufficient to ensure a stable temperature compared to the point D2 where the depth is $8 \mathrm{~m}$ and the temperature (average value: $12.8^{\circ} \mathrm{C}$ ) varies less than $0.5^{\circ} \mathrm{C}$. In the recording period the change of the outer temperature was about $30^{\circ} \mathrm{C}$. It means that shallow boreholes can damp temperature variations significantly. At both boreholes there was no correlation between the tilts and the temperature variations in the boreholes and on the surface. The jumps in the signal of instrument temperature are of instrumental origin and they are rising at the time changing the battery of the instrument.

Since the end of the year 1999 the ground water level has been recorded at the point D2 to investigate the connection between ground tilts and ground water level variations. Till now the length of the ground water level data is short to find any correlation between tilts and water level variations.

Figures 5 and 6 show the tilts of the points D1 and D2 respectively plotted the $\mathrm{Y}$ (north) tilts against the $\mathrm{X}$ (East) ones. Both figures show a "circular" tilt. The diameter of the "circle" is depending on the local disturbances. The greater is the diameter the greater are the local disturbances. If the tilt has a near circular (near closed) form - which means that no significant tilt occurred in any direction then we can suppose that there are no tectonic movements at the point.

Figures 5 and 6 show clearly that the tiltmeter D2 is much more disturbed by local effects than D1. The reason of this is that the whole length of the borehole is almost in loess and therefore the instrument is much more sensitive to local effects than the instrument at the point D1. Figure 7 shows some landslides taking place 


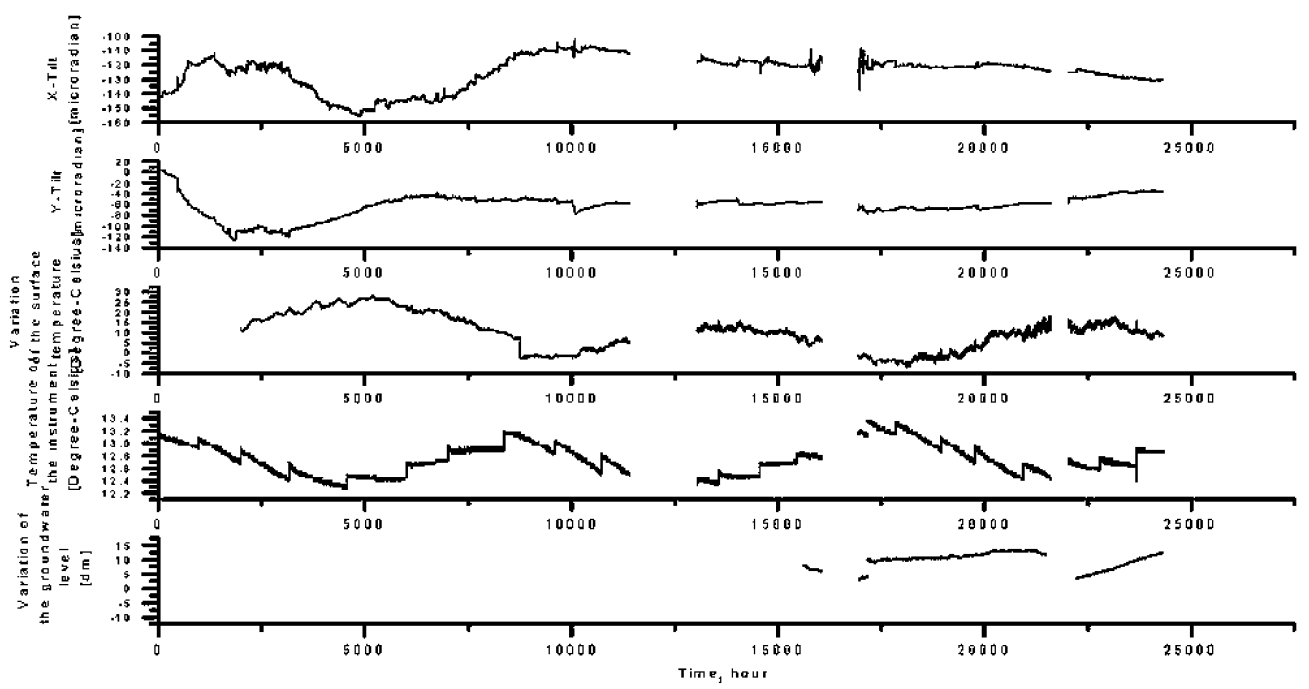

Fig. 4. Row data recorded at the point D2 from 01.01.1998 till 31.12.2000

on the surrounding hills. The processes of landslides are diverse. In the case of the recorded landslides the upper layer of the soil slides after a rain and tilts the tiltmeter moving the upper part of the borehole in direction downward, parallel to the slope. Somewhat later the lower layer of the soil will be also wet and will slide down moving the bottom of the borehole downward decreasing the tilt of the borehole caused by sliding of the upper layer. But it can be that the recorded landslides are not real slides, because the recorded tilts are very small. In this case the increased pore pressure in the upper layer causes tilt and after the seepage of the ground water into the lower layers the pore pressure decreases and the tiltmeter comes back into its original position. To prove these processes longer tilt records and measurements by other methods e.g. (extensometers, hydrological, geophysical and precise geodetic measurements with a high repeatability rate) are needed. Landslides occur always in the seasons with a lot of precipitation, especially in early spring and in autumn. A close correlation can not be found between landslides and the precipitation (Kümpel et al. 2001).

Figure 8 shows a tilt variation caused by the transpiration of the trees of the surrounding forest. The period of the signal is 24 hours. This signal is very similar to the one obtained by pump tests e.g. in Nagycenk in Hungary or Bürvenich in Germany (Kümpel et al. 2001). The level of the groundwater decreases slowly due to the transpiration of the trees and causes a ground tilt. At the night the transpiration of the trees decreases and the groundwater level takes his original level very quickly according to the starting and stopping the pump at the pumtests.

Figure 9 shows an Earth tide signal recorded at the point D1. To prove that the recorded signal is Earth tide we calculated the theoretical tide for the location point D1 by the program ETERNA 3.3 (Wenzel 1996) and plotted it in Fig. 9, too. The calculated Earth tide is in relative unit, its amplitude was divided by a number 


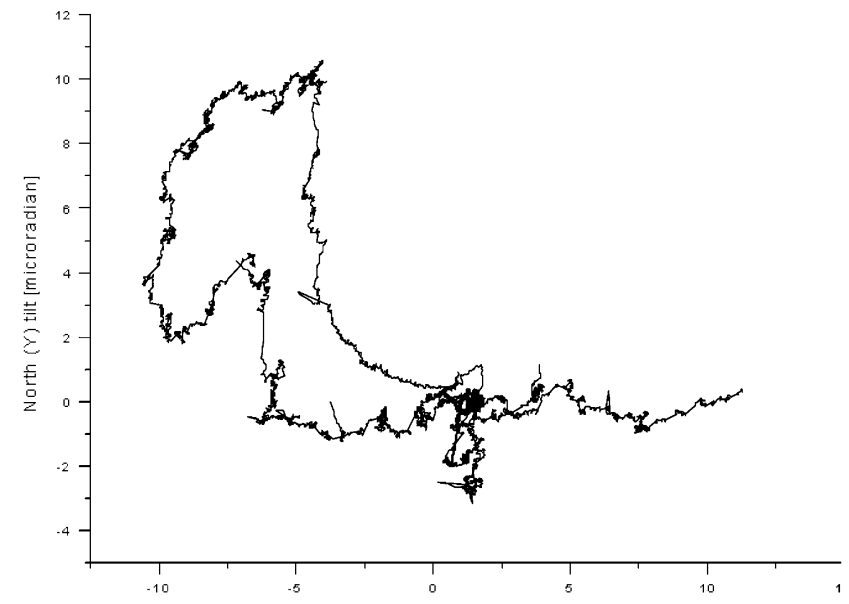

Fig. 5. The tilt of the point D1

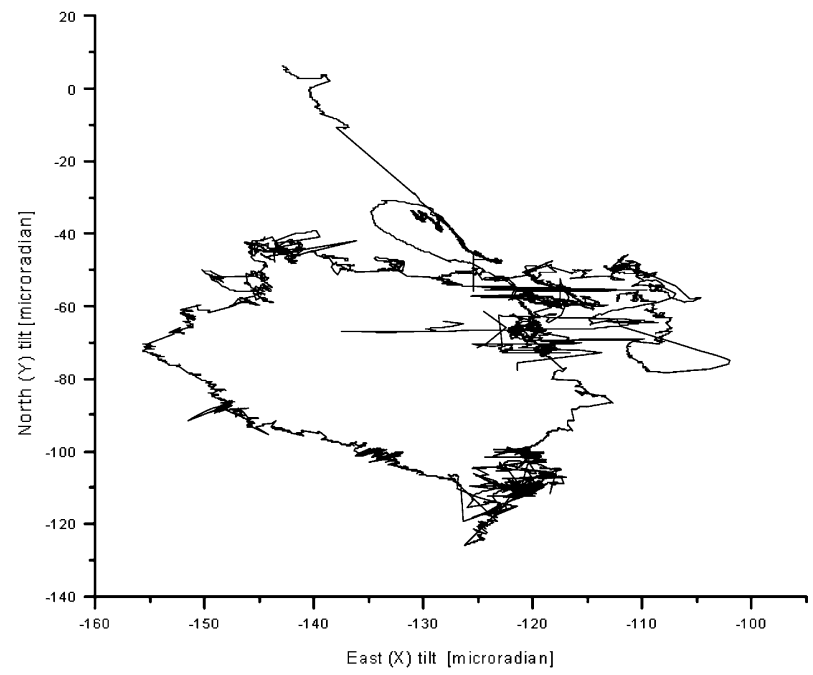

Fig. 6. The tilt of the point D2

so that it could be plotted together with the recorded tilts in a diagram. In the presented time period the Earth tide had an extremely high magnitude and that was the reason that it could be recorded by this tiltmeter which has a resolution of about equal to the usual Earth tide amplitude. In Fig. 9 the close correlation between the theoretical tide and the recorded tilt signals is obvious, especially during high amplitudes of the Earth tide. The reason that at the point D2 no Earth tide was recorded is that this borehole is drilled in sediment and the one at the point D1 is in the bedrock.

On the one hand the recorded disturbing signals prove that the coupling between the ground and the instrument is close, therefore it is suitable for recording 


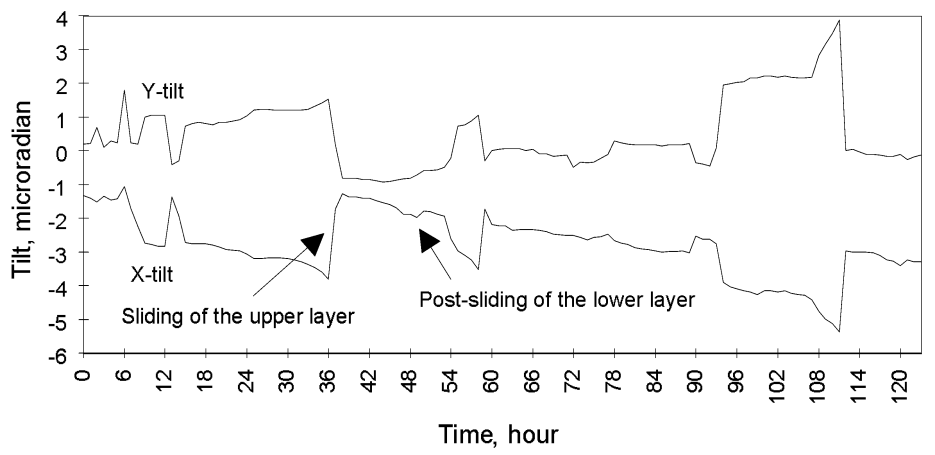

Fig. 7. Landslides recorded at the point D2 from 24.03.1998 till 29.03.1998

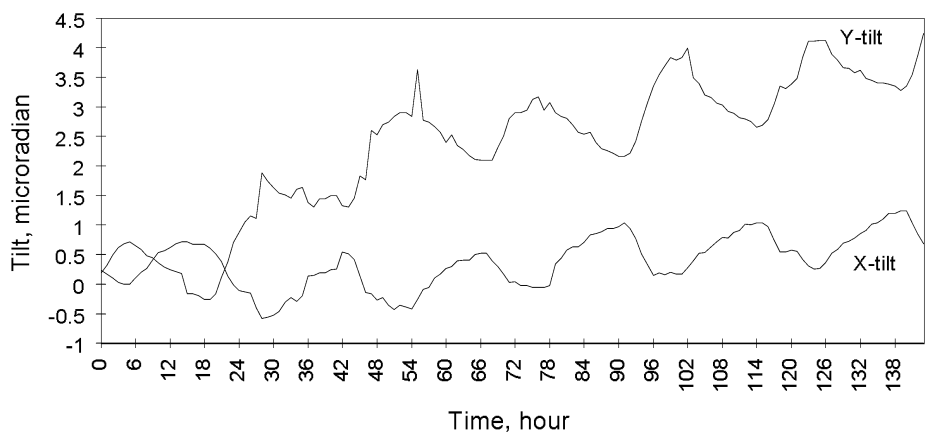

Fig. 8. Tilt caused by the transpiration of the trees recorded at the point D2 from 11.08.1998 till 17.08.1998

geodynamical processes. On the other hand they make the interpretation of the recorded data much more complicated.

The geodetic measurements show no movements of the fault till now because the measured movements are in the range of the precision of the measurements.

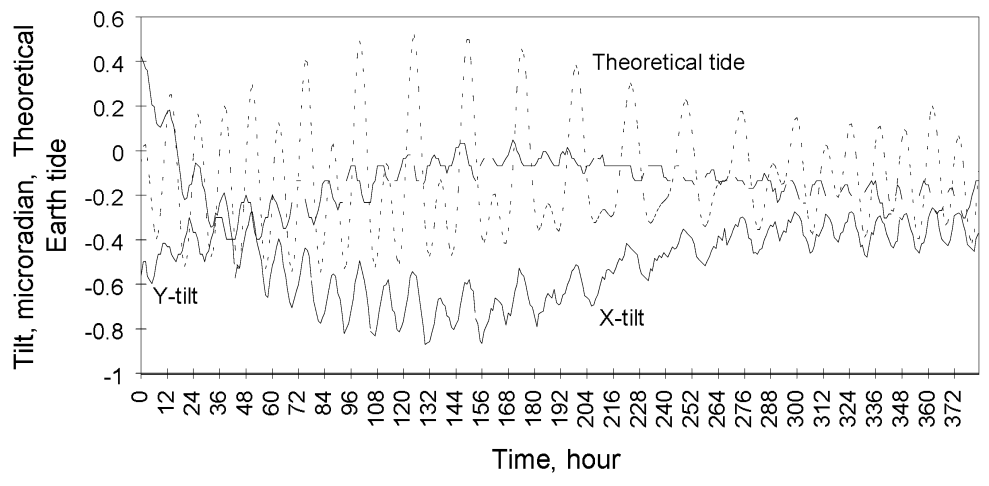

Fig. 9. Earth tide recorded at the point D1 from 12.10. 1997 till 20.10.1997

Acta Geod. Geoph. Hung. 38, 2003 
The results of the yearly twice repeated geodetic measurements have also seasonal variations with an annual period.

\section{Conclusion}

Both the continuous tilt measurements and the repeated geodetic measurements have disturbing effects and in addition the accuracy of the later is less than the movements to be measured. According to our experiences we need some additional recording years at least to eliminate the disturbing effects, to overcome the accuracy problems of the geodetic measurements and to say something about the movements of the fault. For understanding the physical processes of landslides and to avoid the interpretations of landslides as tectonic movements and to develop a system for forecasting landslides a detailed analysis of these processes is needed. For these purposes we decided to establish test territories and develop complex measuring systems both in Hungary and in Austria. On these places complex geodynamical, geodetic, geophysical measurements will be carried out and for the interpretation of the measured data geological, hydrological, meteorological, etc. data will be also used.

\section{Acknowledgements}

This research was supported by grant OTKA T 031713 and by Deputy Under-Secretariate of Ministry of Education for Research and Development and by its foreign contractual partner, Bundesministerium für Auswärtige Angelegenheiten (Hungarian project No. A-2/99) in the frame of the Scientific and Technological Co-operation between Austria and Hungary.

\section{References}

Kümpel H-J, Varga P, Lehmann K, Mentes Gy 1996: Acta Geod. Geoph. Hung., 31, $67-79$.

Kümpel H-J, Lehmann K, Fabian M, Mentes Gy 2001: Geophysical Journal International, $146,1-21$.

Lehmann K, Mentes Gy, Kümpel H-J, Varga P 1998: In: Geodesy for Geotechnical and Structural Engineering, Kahmen, Brückl, Wunderlich eds, Institut für Landesvermessung und Ingenieurgeodäsie, Abteilung Ingenieurgeodäsie, TU Wien, 99-104.

Mentes Gy 1986: Acta Geod. Geoph. Hung., 21, 55-69.

Mentes Gy 1998: In: Proceedings of the 13th International Symposium on Earth Tides, Brussels, 43-50.

Mentes Gy, Lehmann K, Varga P, Kümpel H-J 1996: Acta Geod. Geoph. Hung., 31, 79-89.

Rebscher D 1996: Nachweis von in-situ Bodenverformungen gravitativen und vegetativen Ursprungs mittels Neigungsmessungen in Bonn-Ippendorf. PhD thesis, Faculty of Mathematics and Natural Sciences, University of Bonn

Wenzel H-G 1996: Marees Terrestres Bulletin d'Informations, Bruxelles, 124, 9425-9439. 